City University of New York (CUNY) CUNY Academic Works

\title{
Slavic Psycholinguistics in the 21st Century
}

Irina A. Sekerina

CUNY College of Staten Island

\section{How does access to this work benefit you? Let us know!}

More information about this work at: https://academicworks.cuny.edu/si_pubs/160

Discover additional works at: https://academicworks.cuny.edu

This work is made publicly available by the City University of New York (CUNY).

Contact: AcademicWorks@cuny.edu 


\title{
Slavic Psycholinguistics in the 21st Century*
}

\author{
Irina A. Sekerina
}

Abstract: This article provides an update on research in Slavic psycholinguistics since 2000 following my first review (Sekerina 2006), published as a position paper for the workshop The Future of Slavic Linguistics in America (SLING2K). The focus remains on formal experimental psycholinguistics understood in the narrow sense, i.e., experimental studies conducted with monolingual healthy adults. I review five dimensions characteristic of Slavic psycholinguistics-populations, methods, domains, theoretical approaches, and specific languages-and summarize the experimental data from Slavic languages published in general non-Slavic psycholinguistic journals and proceedings from the leading two conferences on Slavic linguistics, FASL and FDSL, since 2000. I argue that the current research trends in Slavic psycholinguistics are (1) a shift from adult monolingual participants to special population groups, such as children, people with aphasia, and bilingual learners, (2) a continuing move in the direction of cognitive neuroscience, with more emphasis on online experimental techniques, such as eye-tracking and neuroimaging, and (3) a focus on Slavic-specific phenomena that contribute to the ongoing debates in general psycholinguistics. The current infrastructural trends are (1) development of psycholinguistic databases and resources for Slavic languages and (2) a rise of psycholinguistic research conducted in Eastern European countries and disseminated in Slavic languages.

\section{Introduction}

In 2000 I wrote a position paper based on my presentation at the workshop The Future of Slavic Linguistics (SLING2K) that was held at Indiana University (Sekerina 2006). In it I characterized the field of Slavic psycholinguistics as nascent and named the only conference venue where experimental studies of Slavic languages appeared, namely, the Annual Workshop on Formal Approaches to Slavic Linguistics (FASL); then it was the 8th FASL Workshop that took place in 1999. At that time I was also able to list all of the active laboratories in the U.S. and Europe and name most of the established and rising psycholinguists who worked on Slavic languages. The experiments

\footnotetext{
* I wish to thank two anonymous reviewers and Catherine Rudin for their helpful comments and especially suggestions regarding additional sources. All the mistakes are, of course, mine.
} 
that I described encompassed psychophonology, agreement attraction errors in production, lexical production, and sentence processing, but their number was under 20. The overwhelming majority was on Russian, and only a few were on Bulgarian, Polish, and Serbian/Croatian. I finished the review with speculations on future directions that Slavic psycholinguistics may take, i.e., the significant contribution of Slavic data to the ongoing debates in theoretical linguistics, its increased integration into interdisciplinary cognitive science, and emergence of new, Slavic-specific topics.

As we know all too well, offering forecasts especially in science is a risky business. In the 20 years that have passed since the original review, some of my speculations have turned out to be spot-on (e.g., interdisciplinary integration) and some have fallen short (e.g., emergence of new, Slavic-specific topics). This update is necessarily brief, as it is a part of the special issue dedicated to the 25th anniversary of the Journal of Slavic Linguistics that covers many subfields of Slavic linguistics, and it follows in the footsteps of several recent review articles on Slavic languages that provide the backdrop for comparison of the field of Slavic psycholinguistics to Slavic theoretical linguistics (Franks 2009; Lauersdorf 2009; Nedashkivska 2011; Rappaport 2006). Three of those are dedicated to describing what Slavic theoretical linguistics looks like (Franks, Nedashkivska, and Rappaport), while Lauersdorf reviews Slavic sociolinguistics. What comes out loud and clear from them is that psycholinguistics remains on the periphery of Slavic linguistics. In the most recent review, Nedashkivska says that psycholinguistics, together with sociolinguistics and computational linguistics, only "becomes visible [sic]" (509). This conclusion is based on her search for relevant publications in four main Slavic journals, i.e., Journal of Slavic Linguistics, International Journal of Slavic Linguistics and Poetics, Slavic and East European Journal, and Canadian Slavonic Papers (Nedashkivska 2011: Tables 1-4). According to the author, not a single psycholinguistic article was published in them during the period of 1993-2010.

I argue here that although the number of psycholinguistic studies on Slavic languages that appeared from 2000 to the present day is modest, Slavic psycholinguistics is alive and doing well. For example, in 2016, the first edited volume on psycholinguistics of Slavic languages was published (Anstatt et al. 2016). For reasons that have to do with both career development and scientific impact, psycholinguists who work on Slavic languages (and I include myself in this category) prefer to present their work at general psycholinguistic conferences and workshops and publish in psycholinguistic field journals instead of the Slavic ones. Field journals are scholarly, peer-reviewed periodicals that publish research in a particular field of a particular discipline. In general psycholinguistics, such field journals include Cognition, Journal of Memory and Language, and Language, Cognition, and Neuroscience (entitled Cognitive and Linguistic Processes until 2014), just to name a few top ones. They are the most prestigious publication venues for all psycholinguists, regardless of 
the language family, participant group, or choice of methodology. These publication venues, as well as the specialized psycholinguistic conferences such as the CUNY Conference on Sentence Processing (North America) and the Architecture and Mechanisms of Language Processing conference (AMLaP, Europe), are the ones in which Slavic psycholinguists prefer to showcase their experimental work on Slavic languages.

\section{Dimensions of Slavic Psycholinguistics}

Psycholinguistics in the broader sense, just by the mere nature of its interdisciplinary origin at the intersection of psychology and linguistics, is a complex field defined by five dimensions: populations, methods, domains, theoretical approaches, and specific languages. Formal experimental psycholinguistics that investigates language processing by healthy monolingual adults who are native speakers is the core subfield of psycholinguistics in the broader sense. The two-dimensional properties and linear restrictions imposed on this article by its physical format do not do justice to the relationships and interdependence among the dimensions and do not allow for full coverage of every branch and thread in psycholinguistics, even though its focus is on one language family, i.e., that of Slavic languages.

The first three dimensions depicted in Figure 1, i.e., populations, methods, and domains, are unique characteristics of modern general psycholinguistics that it shares with its first parent discipline, that of cognitive psychology, and they set it apart from its other parent discipline, theoretical linguistics. What unites psycholinguistics with the latter are the remaining two dimensions, i.e., theoretical approaches and specific languages. Slavic psycholinguistics in general and formal experimental Slavic psycholinguistics thus mirror that of general psycholinguistics, with the only difference in the fifth and last dimension, namely, its focus on Slavic languages.

\subsection{Populations}

The populations dimension is the most noticeable one; it represents a shift of focus from adult native speakers to special population groups, such as children, people with aphasia, and bilingual learners, both second language (L2) and heritage language (HL) speakers. In fact, since 2000, experimental studies of these three special population groups have outpaced those of monolingual adults and warranted separate articles in this special issue, namely, on first language (L1) acquisition (Ionin and Radeva-Bork this issue) and L2 acquisition of Slavic languages (Gor this issue). As a result, there have been fewer stand-alone experiments with monolingual adults who used to be the main focus of psycholinguistics in the past (e.g., Bott and Gattnar 2015; Levy, Fedo- 


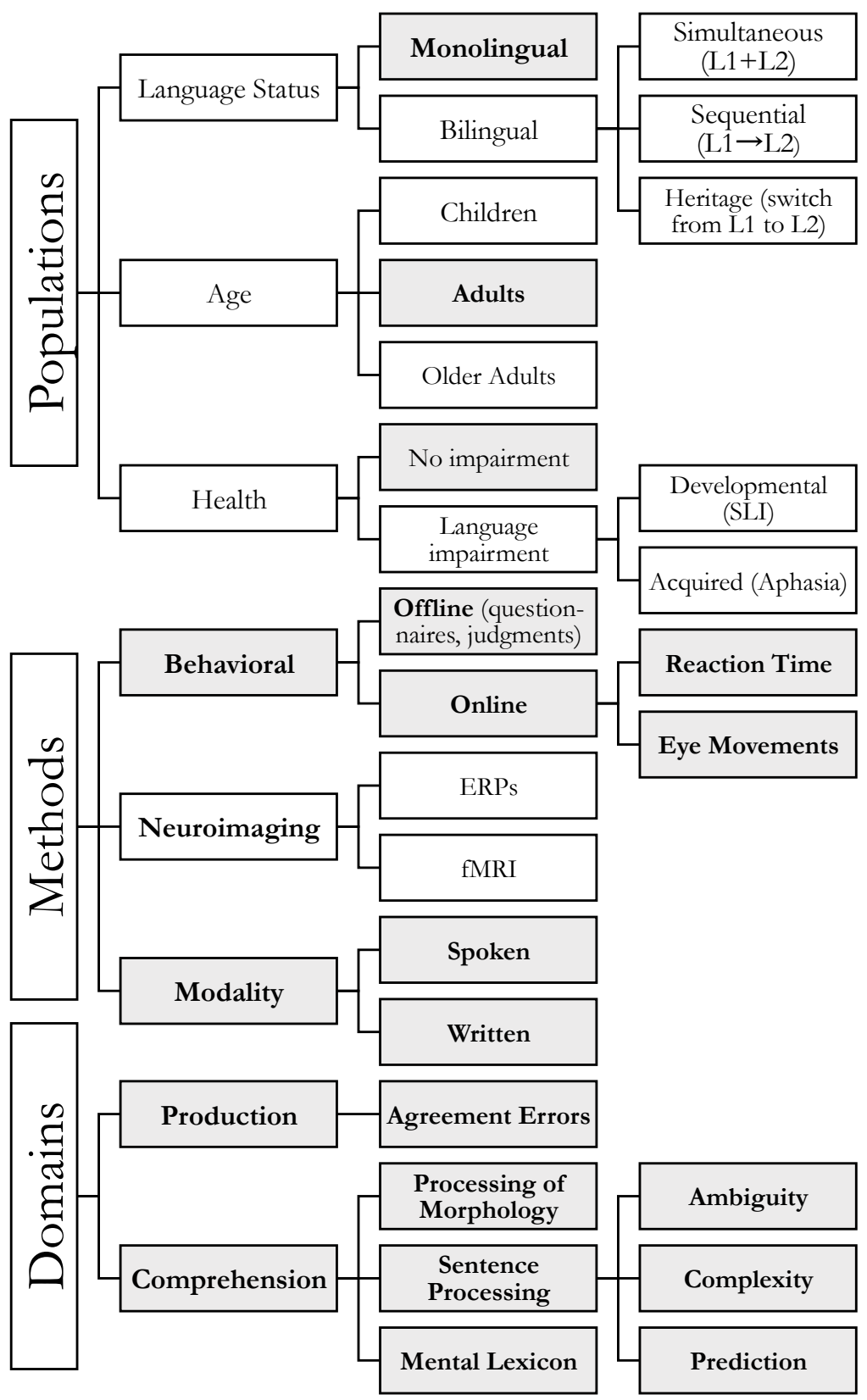

Figure 1. Slavic Psycholinguistics: populations, methods, and domains. Shaded boxes comprise the subfield of formal experimental psycholinguistics. 
renko, and Gibson 2013; Slioussar and Malko 2016). These days, monolingual young adults tend to assume a subordinate status of a control group for the above-mentioned special populations.

Acquisition and processing of Slavic languages as heritage languages, represented mostly by Russian, is unfortunately missing from this special issue. This is despite the fact that HL Russian research occupies a very prominent position in the field of bilingualism thanks to the work of Maria Polinsky (University of Maryland) (see Polinky 2006 for an overview) and some of my own (Sekerina and Sauermann 2015). Acquired (aphasia) and developmental (specific language impairment, SLI) language impairments in Slavic languages also known as neurolinguistics have made substantial gains as well. A steady stream of articles on Russian aphasia from the Laboratory of Neurolinguistics at the Higher School of Economics (HSE) in Moscow (head: Olga Dragoy; Dragoy et al. 2016; Laurinavichyute et al. 2014) and on Russian-speaking SLI children from the research group at Yale University (Rakhlin et al. 2013) deserve a special mention. There are also articles on aphasia and SLI for Bulgarian (Nikolova and Jarema 2004), Czech and Slovak (Marková and Cséfalvay 2010; Smolík and Vávrů 2014), Polish (Jodzio, Biechowska, and Leszniewska-Jodzio 2008), and Serbian (Vuković and Stojanovik 2011; Vuković, Vuković, and Miller 2016). It is clear that Slavic neurolinguistics will continue to grow at a fast pace in the near future.

\subsection{Methods}

The current trend in the methods dimension in psycholinguistics logically follows from rapid growth in cognitive neuroscience. Its subfield, cognitive neuroscience of language, has become so prominent that nowadays experimental studies that use neuroimaging methods, e.g., event-related brain potentials (ERPs), functional magnetic resonance imaging (fMRI), and magnetoencephalography (MEG) supersede the traditional behavioral ones (Fedorenko and Kanwisher 2009). The offline behavioral methods (e.g., grammaticality, preference, and truth-value judgments, sentence-picture matching and verification, and picture selection, among others) that once used to be the staple of psycholinguistics have been relegated to pilot and normative stages of experimental design and play a subordinate role for both online time-sensitive behavioral (e.g., naming, priming, self-paced reading, and eye-tracking) and neuroimaging methods. While not long ago it was possible to write an entire Ph.D. dissertation in psycholinguistics based on mostly offline experiments (Avrutin 1994; Stojanović 1998), the pressure on doctoral students today is to master one or even two online behavioral or neuroimaging techniques (Stoops 2012; Wagner 2011).

The neuroscience push has also resulted in a stratification of psycholinguistic laboratories into those that have access to very expensive fMRI 
equipment (very few), those that have less expensive eye-trackers and/or ERP systems (many), and those that have none (a few). Integration of Slavic psycholinguistics with cognitive neuroscience is gradually taking place in Eastern Europe as well. It has been made possible through the acquisition of external grants or securing institutional funds to buy the equipment necessary to conduct eye-tracking and ERP studies. There are several active eye-tracking laboratories in Russia including the above-mentioned Laboratory of Neurolinguistics (HSE, Moscow), Program in Higher Neurobiology at the Department of Biology (Moscow State University; head: Alexandr V. Latanov), the Laboratory for Cognitive Studies at the Faculty of Liberal Arts (Saint Petersburg State University; head: Tatiana V. Chernigovskaya), and the Program in Psychophysiology at the Department of Social Sciences (Nizhniy Novgorod State University; head: Sofia A. Polevaya). The Center for Experimental Research on Natural Language (University of Wrocław, Poland; head: Joanna Błaszczak) is the largest psycholinguistic laboratory outside of Russia that conducts both eye-tracking and ERP studies on Polish (Tomaszewicz 2013). In several recent articles, ERPs were used to investigate conjunct and object-clitic agreement in Slovenian (Marušič, Nevins, and Badecker 2015) and Croatian (Palmović and Willer-Gold 2016; Pavlinušić and Palmović 2016). Research with fMRI on Slavic languages is rare because it usually requires affiliation with a medical center that uses fMRI equipment for medical purposes, though there are several experiments on the role of morphology in lexical access in Polish from the team at the University of Cambridge (Bozic, Szlachta, and Marslen-Wilson 2013; Szlachta et al. 2012) and in Russian from the Laboratory for Cognitive Studies at the Saint Petersburg State University (Slioussar et al. 2014).

Another trend that is characteristic of general psycholinguistics is a shift from the written to the spoken language (Fig. 1) that can be attributed, for the most part, to the appearance of the visual world eye-tracking paradigm (VWP; Altmann and Kamide 2004). Written materials used to dominate psycholinguistics in general in the 1980-90s, when the most widely used online methods were self-paced reading, cross-modal priming, and eye-tracking in reading. The VWP that is based on the integration of visual context in the form of real objects, pictures, and video clips with spoken materials has made it possible for psycholinguistic research to focus on spoken language comprehension in naturalistic interaction of speakers with the visual world. The work conducted in my laboratory was the first to use the VWP to study language comprehension phenomena in Slavic. In particular, we investigated gender agreement (Sekerina 2012) and processing of universal quantifiers in Russian (Sekerina and Sauermann 2015). Myachykov and colleagues used the VWP in a production experiment that looked at the cost of producing noncanonical word orders in Russian (Myachykov et al. 2013). 


\subsection{Domains}

The domains dimension is by far the most important one because it has to do with topics and themes that constitute the core subject matter of psycholinguistics. It is, of course, an impossible endeavor to survey in full all of the domains of formal experimental psycholinguistics, even if we focus just on Slavic languages. I have chosen several topics from sentence processing that allow me to illustrate noticeable contributions Slavic data have made to ongoing debates (e.g., ambiguity, complexity, and prediction) in formal experimental psycholinguistics. These topics include relative clause attachment ambiguity (Section 2.3.1.), syntactic complexity of object relative clauses (Section 2.3.2.), morphological decomposition in lexical access (Section 2.3.3.), predictive role of morphosyntax (Section 2.3.4.), and agreement attraction errors (Section 2.3.5.). I also list some of the experiments in Slavic psychophonology and psychosemantics. This list is far from complete, as the selection of the experiments reflects my expertise and therefore cannot be comprehensive.

The goal of formal experimental psycholinguistics is to understand the mental mechanisms supporting our remarkable abilities to produce and to understand language with little effort. Therefore it recognizes a number of specific subfields in theoretical linguistics as the most critical in achieving this goal, namely, phonology and phonetics, morphology and lexicon, syntax, semantics, pragmatics, discourse, and their interfaces. The psycholinguistic subfields exist in parallel in production and comprehension and often bear unique names that distinguish them from their theoretical-linguistic counterparts. For example, the core domains of language comprehension include psychophonology, processing of morphology, mental lexicon, experimental semantics, and sentence processing. In the remainder of this article, I focus on Slavic sentence processing leaving a review of other domains for the future.

Sentence processing constitutes perhaps the most well-studied domain in psycholinguistics. It concerns itself with how readers and listeners project structure onto the linear string of words of a sentence to arrive at its meaning. Two classical phenomena-structural ambiguity and syntactic complexitylie at the core of sentence processing research. A string of words is structurally ambiguous if it can be assigned more than one syntactic analysis leading to different meanings. Structurally ambiguous sentences come in two varieties: globally ambiguous (e.g., Visiting relatives could be difficult), where two interpretations are possible, and temporarily ambiguous ones (e.g., The horse raced past the barn fell), where the correct interpretation wins only through reanalysis. Syntactic complexity characterizes some sentences that although perfectly grammatical and unambiguous are difficult to understand because of the unbounded dependencies they contain, e.g., center-embedded sentences (The mouse the cat the dog saw chased ran away) and object relative clauses (The representative that the president denounced slammed the door after the meeting). 


\subsubsection{Relative Clause Attachment Ambiguity}

Slavic sentence processing follows in the footsteps of general sentence processing. It started with the investigation of one type of globally ambiguous sentences, namely, relative clause (RC) attachment ambiguity, in three Slavic languages: Russian (Fedorova, Yudina, and Yanovich 2007; Sekerina 2002), Croatian (Lovrić 2003), and Bulgarian (Sekerina, Fernández, and Petrova 2004). The examples in (1) contain a complex NP1-[of]-NP2-RC string (e.g., syna polkovnika 'the $\operatorname{son}_{A C C}$ [of] the colonel ${ }_{G E N}$ ' in (1a)), in which RC (e.g., kotoryj pogib $v$ avtomobil'noj katastrofe 'who died in a car accident') could structurally attach to either of the two NPs. When the RC modifies the NP1, the sentence means that the son died (high attachment); when it modifies the NP2, it is the colonel who died (low attachment) (Cuetos and Mitchell 1988).

(1) a. Ja znal syna polkovnika, kotoryj pogib v I knew son colonel $_{G E N}$ that NOM $_{\text {died in }}$ avtomobil'noj katastrofe. car accident

(Russian)

'I knew the son of the colonel who died in a car accident.'

b. Nazvali smo kćerku političarke koja phoned are daughter $A C C$ politician dEN $_{\text {that }}$ voli pjevati. likes to sing

(Croatian)

'We phoned the daughter of the politician who likes to sing.'

c. Včera Petâr naj-nakraja sreštna brata na učitelja, yesterday Peter finally met brother of teacher kogoto târseše. (Bulgarian) that looked for 'Yesterday Peter finally met the brother of the teacher whom he was looking for.'

The RC attachment ambiguity received unprecedented attention in general psycholinguistics because it is the only phenomenon that allows for cross-linguistic variation in the otherwise universal principle of Late Closure (LC) of the Garden Path theory of sentence processing (Frazier and Fodor 1978). The LC principle states that new constituents should be attached into the clause or the phrase that is currently being processed. For sentences with the RC attachment ambiguity, the LC Principle favors low attachment preference regardless of the language. However, the experimental studies by Seker- 
ina (2002), Fedorova et al. (2007), Sekerina et al. (2004), and Stoyneshka, Fodor, and Fernández (2010) established that all other things being equal Slavic languages-Russian, Croatian, and Bulgarian-seem to prefer high attachment. In a recent revival of interest in explaining cross-linguistic variation in attachment preferences, Grillo and Costa (2014) singled out the Russian and Bulgarian results as requiring additional attention. According to their theory, high attachment preference in languages is due to the availability of the so-called pseudorelative construction; however, neither Russian nor Bulgarian grammar has them. The explanation of why Russian and Bulgarian exhibit high attachment preference without having pseudorelative clauses remains open. Thus the data on RC attachment ambiguity and other structural ambiguities (e.g., Stoops, Luke, and Christianson 2013) from Slavic languages illustrate how Slavic psycholinguistics could contribute to one of the longest ongoing debates in general psycholinguistics.

\subsubsection{Syntactic Complexity of Object Relative Clauses}

Processing of syntactically complex sentences is yet another area where Slavic languages offer a great opportunity for testing theoretical accounts of why sentences with unbound syntactic dependencies present problems even for monolingual young adults. In such sentences known in psycholinguistics as filler-gap dependencies, a constituent (i.e., a filler) is moved from its original position in the sentence, leaving a trace (i.e., a gap) behind. The necessity to establish this filler-gap dependency in object relative clauses (RC) (e.g., The reporter ${ }_{1}$ that the senator attacked __- hoped for a story) is the cause of errors in comprehension and slower reading times when compared to subject RC (e.g., The reporter that attacked the senator hoped for a story) (Levy, Fedorenko, and Gibson 2013). Two classes of theories have been proposed to account for processing difficulty of the object RC. One is the memory limitations accounts (e.g., the dependency locality theory and cue-based retrieval theory) and the other, the prediction-based ones (e.g., word-order frequency theory and surprisal).

Levy and colleagues 2013 used Russian RCs to tease apart the predictions of the two classes of theories of syntactic complexity by relying on Russian grammar that allows for considerable word order flexibility in any clause, including the RC, and overtly marks cases on noun arguments. They manipulated word order in the subject RC (default SVO vs. scrambled SOV, 2a-b) and object RC (default OSV vs. scrambled OVS, 2c-d) in a self-paced reading study:

(2)

$$
\begin{array}{lllll}
\text { a. Slesar', } & \text { kotoryj udaril èlektrika, ušel domoj. } \\
\text { repairman }_{N O M} & \text { that }_{N O M} & \text { hit } & \text { electrician }_{A C C} & \text { went home }
\end{array}
$$




\section{(2) b. Slesar', kotoryj èlektrika udaril, ušel domoj.}

'The repairman who hit the electrician went home.'
c. Slesar',
kotorogo èlektrik
udaril,
ušel domoj. repairman $_{N O M}$
that $_{A C C}$
electrician $_{N O M}$
hit
went home
d. Slesar',
kotorogo udaril
èlektrik, ušel domoj.

'The repairmen who the electrician hit went home.'

The authors found that in contrast to English, object RCs in Russian were not more difficult to process than subject RCs. This absence of processing difference in RTs is due to the fact that it was possible to disassociate word order from RC type (i.e., subject vs. object) in Russian. However, it took the Russian participants significantly longer to read the embedded verb udaril 'hit' when it was preceded by the NP2 èlektrik/èlektrika 'electrician ${ }_{N O M / A C C}$ ' $(2 \mathrm{~b}-\mathrm{c})$. This result supports the memory-limitations theories because the word èlektrik/ èlektrika 'electrician ${ }_{N O M / A C C}$ ' intervenes between the filler (e.g., slesar' 'repairman') and the gap at the verb and disrupts the filler-gap dependency. At the same time, the NP2 in the nominative case in the object RC (2c) was read faster than when it was in the accusative case in the subject $R C(2 b)$, a finding that is better explained by the expectation-based theories. Thus, Slavic data, once again, support a new approach in explaining syntactic complexity that relies on the integration of the previously competing psycholinguistic theories. It is clear that flexibility of word order of arguments and adjuncts in all types of sentences in Slavic languages (e.g., wh-questions, passives, topicalized sentences) holds the potential to account for many more complexity phenomena initially proposed for languages like English (Slioussar 2011; Stepanov and Stateva 2015).

\subsubsection{Morphological Decomposition in the Mental Lexicon}

In addition to flexible word order, Slavic languages are characterized by rich derivational and inflectional morphology. It is then not surprising that morphology serves as an exciting testing ground for studying the mental lexicon and lexical access in comprehension. Another long-standing debate in general psycholinguistics is about how inflected words are accessed in the mental lexicon. It started with a hypothesis that English verbs in the past tense are retrieved differently depending on whether they are derived via the productive rule of adding an -ed suffix (e.g., walk-walked) or are exceptions to this rule (e.g., eat-ate). Thus, the "words and rules" model by Pinker (1999) argues that the regular forms like walked are accessed via morphological decomposition, whereas the irregular ones like ate that are stored as whole words are accessed by direct sound-to-meaning mapping. 
Experimental data from Slavic languages, with their intricate multilayered and multiaffixed derivational and inflectional morphology, have challenged the dual-mechanism theory of lexical access. Kazanina $(2008,2011)$ found that in Russian both suffixed (e.g., gorka 'a mountain ${ }_{\text {DIMIN }}$ ') and prefixed (e.g., privkus 'aftertaste') inflected words are accessed through morphological decomposition even if they are irregular and semantically nontransparent (e.g., lunka 'hole' and prikol 'prank'). Gor and Jackson (2013) similarly showed that, regardless of their regularity and transparency, prime finite verb forms facilitate access to the target verb infinitive (e.g., regular rabotaju-RABOTAT' 'I work-to work', irregular moju-MYT' 'I wash-to wash') in native speakers of Russian. By manipulating the absence and presence of inflections in Russian nouns, Gor and colleagues (Gor, Chrabaszcz, and Cook 2017) showed that the processing costs in lexical access are not associated with initial decomposition viewed as affix stripping but rather with later recombination and checking of the whole inflected word. In addition, in a series of experiments in Serbian, Feldman, and colleagues (Feldman et al. 2012; Feldman, O'Connor, and Moscoso del Prado Martín 2009) argued that the target words (e.g., RAT and RATAR) were processed faster when the primes and targets were morphologically related (e.g., faster lexical decision times for ratovati-RAT 'to wage war-a war') but not when they were not (e.g., ratovati-RATAR 'to wage war-a peasant). The explanation of what accounts for differences in lexical access of inflected words in Russian and Serbian compared to English remains on the agenda for future psycholinguistic research and perhaps will come from neuroimaging data (Bozic et al. 2013).

\subsubsection{Predictive Role of Morphosyntax}

Morphosyntactic characteristics of Slavic languages hold a very promising potential for testing a new direction in psycholinguistic research that is receiving a lot of attention these days, i.e., real-time prediction in processing. Prediction is crucial not only for processing of ambiguous (Section 2.3.1.) and syntactically complex (Section 2.3.2.) sentences, but also for 'normal' ones (e.g., expecting won upon hearing The prize the athlete ...), because it is well-established in psycholinguistics that readers and listeners actively anticipate upcoming material. This is what lies underneath the robustness and speed of language understanding (Phillips and Ehrenhofer 2015: 413). Investigation of prediction has become particularly fruitful with the rise of eye-tracking, first in reading and later in spoken language comprehension in the form of the visual world eye-tracking paradigm. For example, English listeners can rapidly use selectional restrictions of the verbs to predict the direct objects that are yet to appear in speech stream. Altmann and Kamide 2004 showed that when watching a computer screen with four pictures of a boy, a cake, a toy train, 
and a toy car, the listeners launched eye movements to the cake while still listening to the verb in the spoken sentence The boy will eat the cake.

Note that testing the role of prediction critically relies on early placement of predictive information in the sentence. English with its fixed SVO word order is not best suited for these purposes; in contrast, the flexible word order and rich morphosyntactic paradigms of Slavic languages can be very revealing about which information is predictive in online processing. For example, adjectives that precede nouns in Slavic languages agree with them in gender, number, and case. I used this feature of the Russian grammar to demonstrate that Russian listeners can quickly use the gender agreement marker on the adjective to identify the upcoming target noun (Sekerina 2012). The participants heard the spoken instructions to move colored shapes, e.g., Položite krasnuju ... 'Put the $\operatorname{red}_{\text {FEM-ACC }} .$. ' while looking at the visual display of four shapes, two of which were red objects, a $\operatorname{car}_{F E M}$ and a flower ${ }_{M A S C}$, but of different grammatical gender. Upon hearing the adjective krasnuju 'red $\operatorname{rEM}_{F-A C C}$ ', the listeners were able to quickly launch eye movements to the red car even though they had not heard the word mašinku 'car ${ }_{F E M}$ ' yet. Bott and Gattnar 2015 used eye movements in reading to show that Russian readers were able to predictively use the aspectual information encoded on the perfective verb

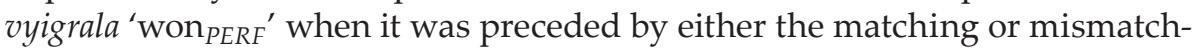
ing durative adverbial (e.g., Celyx tri časa *vyigrala turnir... 'Whole three hours *won the championship...' vs. Tri časa nazad vyigrala turnir ... 'Three hours ago won championship...'). In the mismatching condition, their eye movements reflected immediate detection of the mismatch between the adverbial and the verb, and this allowed them to reject the sentence as not making sense significantly faster than in the matching condition.

Finally, to round off the description of psycholinguistic topics in comprehension with Slavic languages, I should mention experiments in psychophonology and psychosemantics. Russian psycholinguists have studied the role of acoustic cues in the perception of word stress (Chrabaszcz et al. 2014), the use of prosody in deciding whether a sentence is declarative or interrogative (Makarova 2007) and its role in noncanonical word orders (Luchkina and Cole 2014), consonant devocing (Kharlamov 2014), and phonotactic constraints in oral reading of monosyllabic words (Ulicheva et al. 2016). Wagner and colleagues (2013) investigated phonotactic constraints that regulate consonant clusters in Polish. In psychosemantics, Slavic data have been used to study animacy in Serbian (Radanović, Westbury, and Milin 2016), comparative properties of quantifiers in Bulgarian and Polish (Tomaszewicz 2013), and quantifier scope in Russian (Ionin and Luchkina 2015; Sekerina and Sauermann 2015). 


\subsubsection{Agreement Attraction Errors in Production}

I will finish Section 2 with production experiments that investigated Slavic languages. Production traditionally occupies a smaller portion of psycholinguistic research in comparison to language comprehension because it is much more difficult to conduct tightly controlled experiments when participants have to produce language. For production experiments to succeed, it is important to set up a study in such a way that it is possible to restrict participants' free responses to as few categories as possible, which in effect means turning open-ended questions into closed-ended ones. One such topic is agreement attraction errors. In many languages, the subject and the predicate have to agree in grammatical features, although the types of agreement vary among languages. In English, the subject-predicate agreement is reflected in number; when the subject is complex, e.g., the key (NP1) to the cabinets (NP2), people often erroneously produce a predicate that agrees in number with the attractor (NP2) instead of the head (NP1) resulting in an ungrammatical sentence *The key to the cabinets were rusty (Bock et al. 2001). This error is caused by the intervening NP2 that becomes the controller of agreement, i.e., "attracts" it.

Slavic languages offer an advantage to studying agreement attraction errors because the subject and the predicate agree not only in number as in English but also in gender. Lorimor and colleagues (2008) investigated agreement attraction errors in number in Russian and found that the singular-plural condition (e.g., bilet na koncerty 'ticket ${ }_{S G}$ to concerts ${ }_{P L}$ ') produced the most errors similar to English, but in contrast to English, the overall proportion of errors in Russian was much lower ( 0.18 vs. 0.05 , respectively). Agreement attraction errors in gender when the head and the attractor are of different gender (e.g., sosedka muzykanta 'neighbor ${ }_{F E M-N O M}$ musician $_{M A S C-G E N}$ ') in their experiment were almost non-existent (0.006) similar to another Slavic language, Slovak (0.03) (Badecker and Kuminiak 2007). Slioussar and Malko 2016 argued that the standard task must be revised to get participants to produce errors in gender agreement. Instead of using sentence fragment completion, they presented the predicate first (e.g., byl/a/o 'was ${ }_{M A S C / F E M / N E U T}$ ' + participle) followed by the complex subject in which the two NPs were crossed for all possible gender combinations and asked the participants to use them to produce a sentence. Quite a few gender agreement errors were elicited (0.054), with the MASCFEM condition (e.g., recept na maz' *byla... 'prescription MASC for ointment $_{F E M}$ ${ }^{*}{ }^{*}$ as $\left._{F E M} . . . '\right)$ being the worst. The authors argue that agreement attraction errors in gender are due to retrieval interference: speakers generate the nouns inside the complex subject with their grammatical features and then look for specific feature values while retrieving the subject at the verb when they have to produce the right agreement pattern. When this search for specific feature values goes awry, the attractor instead of the head noun becomes the agreement controller, resulting in gender agreement attraction errors. 
Besides attraction errors, gender and number agreement in production has been the focus of experimental research in Bulgarian (Andonova et al. 2004), Czech (Bordag and Pechmann 2009), and Serbian (Mirković and MacDonald 2013). The Journal of Slavic Linguistics $(2016,24.1)$ has recently published a special issue on agreement in Slavic languages that contains six experimental articles on conjunct, object-clitic, and RC-internal agreement in Slovenian, Bosnian/Serbian/Croatian, and Polish (Arsenijević et al. 2016). Psychophonology and prosody were studied in production experiments of Bulgarian acoustic cues of narrow and wide focus (Andreeva, Koleman, and Barry 2014), Slovenian irregular verbs (Petrič and Stemberger, 2014), and Serbian pitch accents (Zsiga and Zec 2013). Patterns of compound-word production in Polish were examined by Haman and colleagues (Haman et al. 2009), while two sentence production studies focused on the role of animacy in relative clauses in Serbian (Gennari, Mirković, and MacDonald 2012) and the cost of producing noncanonical word orders in Russian (Myachykov et al. 2013), respectively.

\subsection{Theoretical Approaches and Specific Languages}

The two final dimensions of Slavic psycholinguistics-theoretical approaches and specific languages-are shared with Slavic theoretical linguistics. The two main theoretical approaches in Slavic linguistics are formal generative and cognitive. Accordingly, Slavic psycholinguistic research falls either into formal experimental or cognitive-linguistic varieties. It is unfortunate that there is a terminological ambiguity: formal experimental psycholinguistics is a happy marriage of generative linguistics and experimental cognitive psychology that started in the late 1950s. However, the adjective "cognitive" is also used in the name of the second theoretical approach, that of cognitive linguistics. The latter is a theoretical linguistic model that emphasizes meaning as opposed to structure and draws on other less formally oriented disciplines, such as semiotics (Evans and Green 2006). This sometimes leads to a confusion in the literature in which psycholinguistics is considered a subfield of cognitive linguistics (Nedashkivska 2011). This is not true of formal experimental psycholinguistics because it takes its roots in generative grammar and closely mirrors the development of Chomsky's linguistic theory (Ferreira 2005). In this article, I have focused on formal experimental psycholinguistics; therefore, I am leaving the description of experimental approaches to Slavic within cognitive linguistics to cognitive linguists (Janda 2006; Janda and Dickey this volume).

The final dimension of Slavic psycholinguistics represents the focus on specific Slavic languages. Out of the three branches of Slavic-East, South, and West-East Slavic languages dominate in psycholinguistic research. This is not surprising because the overwhelming majority of experimental work in Slavic psycholinguistics is on Russian. Among West Slavic languages, the 
dominant one is Polish, with only a few experiments on Czech (Bordag and Pechmann 2009), while the studies in South Slavic languages are mostly on Serbian/Croatian followed by a few on Bulgarian (Andonova et al. 2004; Andreeva et al. 2014; Nikolova and Jarema 2002; Stoyneshka et al. 2010) and Slovenian (Marušič et al. 2015; Petrič and Stemberger 2014). There are single experiments on Slovak (Badecker and Kuminiak 2007) and Ukrainian (Mykhaylyk, Rodina, and Anderssen 2013), and, to the best of my knowledge, no experimental research on Belarussian and Macedonian.

\section{Slavic-specific Academic Infrastructure for Psycholinguistics}

In this final section, I will briefly describe two current trends that drive academic infrastructure growth in Slavic psycholinguistics. The first one is the development of norming databases, sets of visual and spoken materials for conducting empirical studies, and tests and assessments (Section 3.1.). The second trend is an increase in psycholinguistic research that is being carried out in newly established laboratories in the Eastern European countries, with the findings presented at local conferences and often published in Slavic languages (Section 3.2.).

\subsection{Resources for Slavic Psycholinguistics}

Empirical work in psycholinguistics is resource- and labor-intensive. Designing experiments depends on availability of databases of behavioral measures, sets of visual and spoken materials, and tests and assessments. Such resources are readily available for English and many other major European languages. The most important database for any language is its corpus of written and spoken sentences that allow psycholinguists to control for various characteristics of words and naturally occuring syntactic constructions. Such Slavic national corpora are available for Russian (Lyashevskaya and Sharov 2009) and Czech (Český národní korpus). They often serve as the first step in designing materials for psycholinguistic experiments. For example, when we set up an experiment that uses written materials, it is necessary to pay attention to word frequency, their length, and how predictable they are in the sentence. These parameters are especially critical for eye-tracking experiments in reading.

The Neurolinguistics Laboratory at the HSE in Moscow in partnership with the Laboratory for Cognitive Studies at the Saint Petersburg University and my Eye-Tracking Laboratory at the College of Staten Island has used the cross-linguistic protocol for eye movements in reading designed by Reinhold Kliegl (University of Potsdam) (Kliegl et al. 2004) to create the Russian Sentence Corpus (RSC; Laurinavichyute et al. submitted). The RSC contains 144 sentences, and each sentence contains a target word differing according to 
three parameters: length (short, medium, long), frequency (low and high), and part-of-speech (noun, verb, adjective). We collected predictability norms and plausibility ratings for these sentences and then had 100 monolingual skilled readers (ages 18-29) read the RSC sentences. This allowed us to establish basic characteristics of eye movements in Russian (fixation durations, landing positions, word skipping probabilities) as factors of frequency, length, part-ofspeech, and predictability. The RSC and the database of eye movements will be available as a free repository on the web site of the Laboratory of Neurolinguistics at HSE and will serve eye-movement norms for skilled readers for comparison with eye-movement patterns in adult learners, i.e., Russian heritage speakers and L2 learners of Russian (https://www.hse.ru/neuroling/eyetracking_materials).

Other newly developed psycholingustic resources for Russian include a database of linguistic parameters of words SimulStat (http://stimul.cognitivestudies. ru/ru_stimul/) and a database of pictures of 375 action nouns and verbs (Akinina et al. 2015, http://en.stimdb.ru/). The norms for age of acquisition, name agreement, picture name agreement, imageability, familiarity, word frequency, and word length for the most widely used picture set in general psycholinguistics by Snodgrass and Vanderwart (1980) are also available for Russian (Bonin, Guillemard-Tsarapina, and Méot 2013; Grigoriev and Oshhepkov 2013) and Croatian (Rogić et al. 2013). Lists of pseudowords are very useful for crossmodal priming experiments that rely on a lexical decision task; one such list is available for Polish (Imbir, Spustek, and Żygierewicz 2015).

\subsection{Slavic Psycholinguistics in the Eastern European Countries}

So far I have reviewed the state-of-the-art of Slavic psycholinguistics as it can be gleaned from empirical peer-reviewed publications in the western journals that are indexed in Web of Science ${ }^{\mathrm{TM}}$ and Scopus ${ }^{\mathrm{TM}}$. Such articles are easily accessible in the academic electronic databases through university libraries and are written in English. However, much of psycholinguistic research on Slavic languages appears in the proceedings of Slavic conferences and country-specific academic journals. The proceedings are always in English, whereas country-specific journals are often published in a Slavic language which make them less accessible to the readers outside of the Slavic world.

In addition to the most important Slavic conference held in the U.S. annually, i.e., Formal Approaches to Slavic Linguistics Workshop (FASL, with the 26th meeting held in 2017), there is a biannual European partner conference Formal Description of Slavic Languages (FDSL, with the 12th meeting held in 2016). Each FDSL conference features several talks that present psycholinguistic experiments on Slavic languages. For example, between FDSL-4 (2001) and FDSL-11 (2015), there were talks on negation and aspect in Bulgarian (Kühnast 2003), superiority effects and wh-questions in Russian (Meyer 2002), 
prosody and focus in Bulgarian (Oliver and Andreeva 2004), grammatical gender in Czech (Bordag 2008) and Russian (Sekerina 2008), relative clause attachment ambiguity in Russian (Fedorova et al. 2007), and neg-raising in Slovenian (Dočekal and Dotlačil 2015), just to name a few. Moreover, the three recent FDSL conferences hosted special psycholinguistic workshops on heritage Slavic languages (FDSL-10 in 2013 in Leipzig), first language acquisition of Slavic languages (FDSL-11 in 2015 in Potsdam), and on experimental semantics and pragmatics (FDSL-12 in 2016 in Berlin). The FDSL proceedings, a selection of the talks, are published in English by Peter Lang, a German publisher.

Publishing special issues dedicated to a particular topic relevant to Slavic linguistics in Slavic journals presents an excellent opportunity for bringing psycholinguists to the forefront. One such example is the 32nd volume of Cahiers Linguistiques d'Ottawa entitled Psycholinguistics in Slavic for which Danijela Stojanović served as a guest editor (Stojanović 2004). This volume contains seven articles that describe experiments in a variety of Slavic languages (e.g., Russian, Czech, Polish, and Ukrainian), range from psychophonology to agreement to sentence processing, and investigate a variety of special populations such as children and bilingual speakers. The Slavic professional organization, the Slavic Linguistics Society (SLS), founded in 2004, that convenes its own annual conference, has made the premier publication venue for Slavic linguistics, the Journal of Slavic Linguistics, its official journal, and more Slavic psycholinguistic articles now appear there. Psycholinguistic coverage in JSL is still modest, but a recent issue, 24(1), contains a collection of six articles dedicated to experimental investigations of agreement in South Slavic (Arsenijević et al. 2016).

Finally, several country-specific journals publish psycholinguistic articles in the Slavic language of the country. For example, Voprosy jazykoznanija 'Issues in Linguistics', a journal of the Russian Academy of Sciences, has published several such articles in Russian by the two leading Russian psycholinguists, Olga V. Fedorova and Olga V. Dragoy, who work in Moscow (Dragoy 2006; Fedorova 2013). The Polish Academy of Sciences has an official journal, Polish Psychological Bulletin, and the University of Ljubljana has a Slovenian journal Linguistica, where psycholinguistic articles appear (Dočekal and Dotlačil 2015; Hamam et al. 2009) both in English and in Slavic languages. New e-journals create new opportunities for Slavic psycholinguists to make their work accessible to a wider audience. One such example is the Questions and Answers in Linguistics journal published jointly by the University of Wrocław and Mouton de Gruyter. One particular open-access journal where several psycholinguistic articles on Slavic languages have recently appeared (Imbi et al. 2015; Slioussar and Malko 2016; Stepanov and Stateva 2015) is Frontiers in Psychology: Language Sciences (http://journal.frontiersin.org/journal/psychology/section/ language-sciences). Despite the fact that it has expensive article processing 
charges, this open-access peer-reviewed journal is rapidly gaining popularity. Since its foundation seven years ago, it has become the largest and the second most cited journal in psychology, with an impact factor of 2.463. The fact that psycholinguistic articles on Slavic languages have started to appear in Frontiers in Psychology is an encouraging testimony to the high quality, interdisciplinary nature, and bright future perspectives for Slavic psycholinguistics.

\section{References}

Akinina, Yulia, Svetlana Malyutina, Maria Ivanova, Ekaterina Iskra, Elena Mannova, and Olga Dragoy. (2015) “Russian normative data for 375 action pictures and verbs". Behavior research methods 47(3): 691-707.

Altmann, Gerry T. M. and Yuki Kamide. (2004) "Now you see it now you don't: Mediating the mapping between language and the visual world". John M. Henderson and Fernanda Ferreira, eds. The interface of language, vision, and action: Eye movements and the visual world. New York: Psychology Press, 347-68.

Andonova, Elena, Simona D'Amico, Antonella Devescovi, and Elizabeth Bates. (2004) "Gender and lexical access in Bulgarian". Perception and psychophysics 66(3): 496-503.

Andreeva, Bistra, Jacques Koleman, and William Barry. (2014) "Local and global acoustic correlates of information structure in Bulgarian". Nick Campbell, Dafydd Gibbon, and Daniel Hirst, eds. Proceedings of Speech Prosody 2014, special session on prosody of Slavic languages. 20-23 May. Dublin, Ireland. Available at: http://www.coli.uni-saarland.de/ andreeva/publications.htm.

Anstatt, Tanja, Anja Gattnar, and Christina Clasmeier, eds. (2016) Slavic langauages in psycholinguistics: Chances and challenges for empirical and experimental research. Tübingen: VerlagNarr/Francke/Attempto.

Arsenijević, Boban, Marijana Kresić, Nedžad Leko, Andrew Nevins, and Jana Willer-Gold. (2016) "Agreement phenomena in Slavic languages". Journal of Slavic linguistics 24(1): 1-5.

Avrutin, Sergey. (1994) Psycholinguistic investigations in the theory of reference. Ph.D. dissertation, Massachusetts Institute of Technology.

Badecker, William and Frantisek Kuminiak. (2007) "Morphology, agreement, and working memory retrieval in sentence production: Evidence from gender and case in Slovak". Journal of memory and language 56: 65-85.

Bock, Kathryn, Kathleen M. Eberhard, Cooper J. Cutting, Antje S. Meyer, and Herbert Schriefers. (2001) "Some attractions of verb agreement". Cognitive psychology 43(2): 83-128.

Bonin, Patrick, Diana Guillemard-Tsarapina, and Alain Méot. (2013) “Determinants of naming latencies, object comprehension times, and new norms 
for the Russian standardized set of the colorized version of the Snodgrass and Vanderwart pictures". Behavior research methods 45: 731-45.

Bordag, Denisa and Thomas Pechmann. (2009) "Externality, internality, and (in)dispensability of grammatical features in speech production: Evidence from Czech declension and conjugation". Journal of experimental psychology: Learning, memory, and cognition 35(2): 446-65.

Bott, Oliver and Anja Gattnar. (2015) "The cross-linguistic processing of aspect: An eyetracking study on the time course of aspectual interpretation in Russian and German". Language, cognition, and neuroscience 30(7): 877-98.

Bozic, Mirjana, Zanna Szlachta, and William D. Marslen-Wilson. (2013) "Cross-linguistic parallels in processing derivational morphology: Evidence from Polish". Brain and language 127(3): 533-38.

Český Národní Korpus. Avaialable at: https://www.korpus.cz/.

Chrabaszcz, Anna, Matthew Winn, Candise Y. Lin, and William J. Idsardi. (2014) "Acoustic cues to perception of word stress by English, Mandarin, and Russian speakers". Journal of speech, language, and hearing research 57(4): 1468-79.

Dočekal, Mojmír and Jakub Dotlačil. (2015) "Experimental evidence for neg-raising in Slavic". Linguistica 56(1): 93-109. Available at: http://revije. ff.uni-lj.si/linguistica.

Dragoy, Olga V. (2006) “Razrešenie sintaksičeskoj mnogoznačnosti: Pravila i verojatnosti ['Resolution of syntactic ambiguity: Rules and probabilities']". Voprosy jazykoznanija 6: 44-61.

Dragoy, Olga, Mira Bergelson, Ekaterina Iskra, Anna Laurinavichyute, Elena Mannova, Anatoliy Skvortsov, and Aleksandr Statnikov. (2016) "Comprehension of reversible constructions in semantic aphasia". Aphasiology 30(1): 1-22.

Evans, Vyvyan and Melanie Green. (2006) Cognitive linguistics: An introduction. Edinburgh: Edinburgh University Press.

Fedorenko, Evelina and Nancy Kanwisher. (2009) "Neuroimaging of language: Why hasn't a clearer picture emerged?" Language and linguistics compass 3(4): 839-65.

Fedorova, Olga V. (2013) “Ob èksperimental'nom sintaksise i sintaksičeskom èksperimente v jazykoznanii [’On experimental syntax and syntactic experiments in linguistics']". Voprosy jazykoznanija 1: 3-21.

Fedorova, Olga V., Maria Yudina, and Igor S. Yanovich. (2007) "Relative clause attachment in Russian: The role of conceptual and grammatical gender". Peter Kosta and Lilia Schurcks, eds. Linguistic investigations into formal description of Slavic languages. Frankfurt: Peter Lang, 91-100.

Feldman, Laurie B., Patrick A. O'Connor, and Fermín Moscoso del Prado Martín. (2009) "Early morphological processing is morphosemantic and 
not simply morpho-orthographic: A violation of form-then-meaning accounts of word recognition". Psychonomic bulletin and review 16: 684-91.

Feldman, Laurie B., Aleksandar Kostić, Vasilije Gvozdenović, Patrick A. O'Connor, and Fermín Moscoso del Prado Martín. (2012) "Semantic similarity influences early morphological priming in Serbian: A challenge to form-then-meaning accounts of word recognition". Psychonomic bulletin and review 19(4): 668-76.

Ferreira, Fernanda. (2005) "Psycholinguistics, formal grammars, and cognitive science". The linguistic review 22: 365-80.

Franks, Steven. (2009) "State-of-the-field: Slavic linguistics". AATSEEL newsletter 52(4): 2-3. Available at: http://www.aatseel.org/100111/pdf/aatseeldec09nl.pdf.

Frazier, Lyn and Janet D. Fodor. (1978) "The sausage machine: A new twostage parsing model". Cognition 6: 291-325.

Gennari, Silvia P., Jelena Mirković, and Maryellen C. MacDonald. (2012) "Animacy and competition in relative clause production: A cross-linguistic investigation". Cognitive psychology 65(2): 141-76.

Gor, Kira. (this issue) "The mental lexicon of L2 learners of Russian: Phonology and morphology in lexical storage and access". Journal of Slavic linguistics 25(2): 277-302.

Gor, Kira, Anna Chrabaszcz, and Svetlana Cook. (2017) "Processing of native and nonnative inflected words: Beyond affix stripping". Journal of memory and language 93: 315-32.

Gor, Kira and Scott Jackson. (2013) "Morphological decomposition and lexical access in a native and second language: A nesting doll effect". Language and cognitive processes 28(7): 1065-91.

Grigoriev, Andrei and Ivan Oshhepkov. (2013) “Objective age of acquisition norms for a set of 286 words in Russian: Relationships with other psycholinguistic variables". Behavior research methods 45: 1208-17.

Grillo, Nino and João A. Costa. (2014) "Novel argument for the universality of parsing principles". Cognition 13(1): 156-87.

Haman, Ewa, Andrea Zevenbergen, Melissa Andrus, and Marta Chmielewska. (2009) "Coining compounds and derivations: A crosslinguistic elicitation study of word-formation abilities of preschool children and adults in Polish and English". Polish psychological bulletin 40(4): 176-92. Available at: https://www.degruyter.com/view/j/ppb.2009.40.issue-4/s10059-009-0013-3/ s10059-009-0013-3.xml.

Imbir, Kamil K., Tomasz Spustek, and Jarosław Żygierewicz. (2015) "Polish pseudo-words list: Dataset of 3023 stimuli with competent judges' ratings". Frontiers in psychology, 6. ArtID: 1395.

Ionin, Tania and Tatiana Luchkina. (2015) "One reading for every word order: Revisiting Russian scope". Ulrike Steindl et al., eds. Proceedings of the 32nd West Coast Conference on Formal Linguistics. University of South California, 
March 7-9, 2014. Somerville, MA: Cascadilla Proceedings Project, 21-30. Available at: www.lingref.com/cpp/wccfl/32/paper3153.pdf.

Ionin, Tania and Teodora Radeva-Bork. (this issue) "The state of the art of first language acquisition research on Slavic languages". Journal of Slavic linguistics 25(2): 337-366.

Janda, Laura. (2006) "Cognitive linguistics". Steven Franks, Edna Andrews, Ron Feldstein, and George Fowler, eds. Slavic linguistics 2000: The future of Slavic linguistics in America. Glossos 8. Available at: http://slaviccenters.duke. edu/projects/glossos-journal/issues/issue-8.

Janda, Laura and Tore Nesset. (this issue) "Cognitive linguistics: A neat theory for messy data". Journal of Slavic linguistics 25(2): 367-385.

Jodzio, Krzysztof, Daria Biechowska, and Barbara Leszniewska-Jodzio. (2008) "Selectivity of lexical-semantic disorders in Polish-speaking patients with aphasia: Evidence from single-word comprehension". Archives of clinical neuropsychology 23(5): 543-51.

Kazanina, Nina. (2011) "Decomposition of prefixed words in Russian". Journal of experimental psychology: Learning, memory, and cognition 37(6): 1371-90.

Kazanina, Nina, et al. (2008) “Decomposition into multiple morphemes during lexical access: A masked priming study of Russian nouns". Language and cognitive processes 23(6): 800-23.

Kharlamov, Viktor. (2014) "Incomplete neutralization of the voicing contrast in word-final obstruents in Russina: Phonological, lexical, and methodological influences". Journal of phonetics 43: 47-56.

Kliegl, Reinhold, Ellen Grabner, Martin Rolfs, and Ralf Engbert. (2004) "Length, frequency, and predictability effects of words on eye movements in reading". European journal of cognitive psychology 16(1-2): 262-84.

Kühnast, Milena. (2003) "Processing negation and aspect in Bulgarian. Evidence from normal and agrammatic sentence comprehension". Peter Kosta et al., eds. Investigations into formal Slavic linguistics: Part II. Frankfurt: Peter Lang, 419-40.

Lauersdorf, Mark Richard. (2009) "Slavic sociolinguistics in North America: Lineage and leading edge". Journal of Slavic linguistics 17(1-2): 3-60.

Laurinavichyute, Anna, Irina A. Sekerina, Kristina Bagdasaryan, Svetlana Alexeeva, and Nikita Zmanovksy. (Submitted) "Russian Sentence Corpus: Benchmark measures of eye movements in reading in Cyrillic". International journal of corpus linguistics.

Laurinavichyute, Anna, Anastasya Ulicheva, Maria Ivanova, Svetalana Kuptsova, and Olga Dragoy. (2014) "Processing lexical ambiguity in sentential context: Eye-tracking data from brain-damaged and non-braindamaged individuals". Neuropsychologia 64: 360-73.

Levy, Roger, Evelina Fedorenko, and Edward Gibson. (2013) "Syntactic complexity in Russian relative clauses". Journal of memory and language 69: 461-95. 
Lorimor, Heidi, Kathryn Bock, Ekaterina Zalkind, Alina Sheyman, and Robert Beard. (2008) "Agreement and Attraction in Russian". Language and cognitive processes 23(6): 769-99.

Lovrić, Nenad. (2003) Implicit prosody in silent reading: Relative clause attachment in Croatian. Ph.D. dissertation, The City University of New York.

Luchkina, Tatiana and Jennifer S. Cole. (2014) "Structural and prosodic correlates of prominence in free word order language discourse". Nick Campbell, Dafydd Gibbon, and Daniel Hirst, eds. Proceedings of the 2014 Meeting of the Speech Prosody Conference (SP 7), Dublin, Ireland, 20-23 May.

Lyashevskaya, Olga N. and Sergey A. Sharov. (2009) Častotnyj slovar' sovremennogo russkogo jazyka (na materialax nacional'nogo Korpusa Russkogo Jazyka. [Frequency dictionary of Modern Russian (based on the materials of the Russian National Corpus)]. Moscow: Azbukovnik.

Makarova, Veronika. (2007) "The effect of pitch peak alignment on sentence type identification in Russian". Language and speech 50(3): 385-422.

Marková, Jana and Zsolt Cséfalvay. (2010) "Morphological-syntactic deficits in the production of Slovak-speaking patients". Aphasiology 24(10): 1197-222.

Marušič, Franc, Andrew Nevins, and Bill Badecker. (2015) "The grammars of conjunction agreement in Slovenian". Syntax 18(1): 39-77.

Meyer, Roland. (2002) "Wh-questions without overt wh-movement in Russian and Polish". Peter Kosta and Joseph Frasek, eds. Current approaches to formal Slavic linguistics. Contributions of the 2nd European Conference on Formal Description of Slavic Languages (FDSL II). Frankfurt: Peter Lang, 317-26.

Mirković, Jelena and Maryellen C. MacDonald. (2013) "When singular and plural are both grammatical: Semantic and morphophonological effects in agreement". Journal of memory and language 69(3): 277-98.

Myachykov, Andrij, Christoph Scheepers, Simon Garrod, Dominic Thompson, and Olga Fedorova. (2013) "Syntactic flexibility and completion in sentence production: The case of English and Russian". The quarterly journal of experimental psychology 66(8): 1601-19.

Mykhaylyk, Roksolana, Yulia Rodina, and Merete Anderssen. (2013) “Ditransitive constructions in Russian and Ukrainian: Effect of givenness on word order". Lingua 137: 271-89.

Nedashkivska, Alla. (2011) "The metropolis of Slavic linguistics in North America and its development over the past two decades". Canadian Slavonic papers $53(2-4)$ : $485-511$.

Nikolova, Rossitza and Gonia Jarema. (2002) “The role of morphological structure in the processing of aspectual verb forms in a Bulgarian-speaking aphasic patients". Journal of neurolinguistics 17(5): 349-69.

Oliver, Dominika and Bistra Andreeva. (2004) "Peak alignment in broad and narrow focus in Polish and Bulgarian: A cross-language study". Proceedings of the 5th Conference on Formal Description of Slavic Languages, Leipzig 26-28, November 2003. 
Palmović, Marijan and Jana Willer-Gold. (2016) “Croatian mixed-gender conjunct agreement: An ERP study". Journal of Slavic linguistics 24(1): 137-60.

Pavlinušić, Eva and Marijan Palmović. (2016) “Object-clitic agreement in Croatian: An ERP study". Journal of Slavic linguistics 24(1): 161-85.

Petrič, Teodor and Joseph P. Stemberger. (2014) "Permanent and temporary phonological influences in Slovenian irregular verb production". Language, cognition, and neuroscience 29(4): 470-82.

Phillips, Colin, and Lara Ehrenhofer. (2015) "The role of language processing in language acquisition". Linguistic approaches to bilingualism 5(4): 409-53.

Pinker, Steven. (1999) Words and rules. New York: Harper Perennial.

Polinsky, Maria. (2006) "Incomplete acquisition: American Russian". Journal of Slavic linguistics 14(1): 191-262.

Radanović, Jelena, Chris Westbury, and Petar Milin. (2016) "Quantifying semantic animacy: How much are words alive?" Applied psycholinguistics 37(6): 1477-99.

Rakhlin, Natalia, Sergey A. Kornilov, Dean Palejev, Roman A. Koposov, Joseph T. Cheng, and Elena L. Grigorenko. (2013) “The language phenotype of a small geographically isolated Russian-speaking population: Implications for genetic and clinical studies of developmental language disorder". Applied psycholinguistics 34(5): 971-1003.

Rappaport, Gilbert C. (2006) "Slavic and East European linguistics in SEEJ: A half-century of scholarship". Slavic and East European journal 50(1): 97-116.

Rogić, Maja, Ana Jerončić, Marija Bošnjak, Ana Sedlar, Darko Hren, and Verdan Deletis. (2013) "A visual object naming task standardized for the Croatian language: A tool for research and clinical practice". Behavior research methods 45(4): $1144-58$.

Sekerina, Irina A. (2002) "The late closure principle vs. the balance principle: Evidence from on-line processing of ambiguous Russian sentences". Peter Costa and Joseph Frasek, eds. Current approaches to formal Slavic linguistics. Contributions of the 2nd European Conference on Formal Description of Slavic Languages. Potsdam Meeting 1999. Frankfurt: Peter Lang, 205-17.

. (2006) "Building bridges: Slavic linguistics going cognitive". Steven Franks, Edna Andrews, Ron Feldstein, and George Fowler, eds. Slavic linguistics 2000: The future of Slavic linguistics in America. [Special issue Glossos 8]. Available at: http://www.seelrc.org/glossos/issues/8/sekerina.pdf.

. (2012) "The effects of grammatical gender in Russian spoken-word recognition". Veronika Makarova, ed. Russian language studies in North America: New perspectives from theoretical and applied linguistics. UK: Anthem Press, 107-30.

Sekerina, Irina A. and Antje Sauermann. (2015) "Visual attention and quantifier-spreading in heritage Russian bilinguals". Second language research 31(1): 75-104. 
Sekerina, Irina A., Eva M. Fernández, and Krassimira A. Petrova. (2004) "Relative clause attachment in Bulgarian". Olga Arnaudova et al., eds. The Proceedings of the 12th FASL Workshop. The Ottawa Meeting 2003. Ann Arbor: Michigan Publications, 375-94.

Slioussar, Natalia. (2011) "Processing of a free word order language: The role of syntax and context". Journal of psycholinguistic research 40(4): 291-306.

Slioussar, Natalia, Maxim V. Kireev, Tatiana V. Chernigovskaya, Galina V. Kataeva, Alexander D. Korotkov, and Svyatoslav V. Medvedev. (2014) "An ER-fMRI study of Russian inflectional morphology". Brain and language 130: 33-41.

Slioussar, Natalia and Anton Malko. (2016) "Gender agreement attraction in Russian: Production and comprehension evidence" Frontiers in psychology 7. ArtID 1651.

Smolík, Filip and Petra Vávrů. (2014) "Sentence imitation as a marker of SLI in Czech: Disproportionate impairment of verbs and clitics". Journal of speech, language, and hearing research 57(3): 837-49.

Snodgrass, Joan G. and Mary Vanderwart. (1980) "A standardized set of 260 pictures: Norms for name agreement, image agreement, familiarity, and visual complexity". Journal of experimental psychology: Human learning and memory 6(2): 174-215.

Stepanov, Arthur and Penka Stateva. (2015) "Cross-linguistic evidence for memory storage costs in filler-gap dependencies with wh-adjuncts" Frontiers in psychology 6. ArtID 1301.

Stojanović, Danijela. (1998) Parsing and acquisition: Evidence from Serbo-Croatian. Ph.D. dissertation, University of Ottawa.

_ ed. (2004) "Psycholinguistics in Slavic". Cahiers linguistiques d'Ottawa 34: 1-142.

Stoops, Anastasia A. (2012) Parafovial preview during reading in Russian: Native speakers and second language learners. Ph.D. dissertation, University of Illinois at Urbana-Champaign.

Stoops, Anastasia, Steven G. Luke, and Kiel Christianson. (2013) "Animacy information outweighs morphological cues in Russian". Language, cognition, and neuroscience 29(5): 584-604.

Stoyneshka, Iglika, Janet Dean Fodor, and Eva M. Fernández. (2010) “Phoneme restoration methods for investigating prosodic influences on syntactic processing". Language and cognitive processes 25(7-9): 1265-93.

Tomaszewicz, Barbara. (2013) “Linguistic and visual cognition: Verifying proportional and superlative most in Bulgarian and Polish". Journal of logic, language, and information 22(3): 335-56.

Ulicheva, Anastasia, Max Coltheart, Steven Saunders, and Conrad Perry. (2016) "Phonotactic constraints: Implications for models of oral reading in Russian". Journal of experimental psychology: Learning, memory, and cognition 42(4): 636-56. 
Vuković, Mile and Vesna Stojanovik. (2011) "Characterising developmental language impairment in Serbian-speaking children: A preliminary investigation". Clinical linguistics and phonetics 25(3): 187-97.

Vuković, Mile, Irena Vuković, and Nick Miller. (2016) "Acquired dyslexia in Serbian speakers with Broca's and Wernicke's aphasia". Journal of communication disorders 61: 106-18.

Wagner, Monica. (2011) Early and late stages of neural speech processing in native-English and native-Polish listeners: A behavioral and ERP study. Ph.D. dissertation, The City University of New York.

-. (2013) "The effect of native-language experience on the sensory-obligatory components, the P1-N1-P2 and the T-complex". Brain research 1522: 31-37.

Willer-Gold, Jana et al. (2016) "Conjunct agreement and gender in South Slavic: From theory to experiments to theory". Journal of Slavic linguistics 24(1): 187-224.

Zsiga, Elizabeth and Draga Zec. (2013) "Contextual evidence for the representation of pitch accents in standard Serbian". Language and speech 56(1): 69-104.

College of Staten Island 2800 Victory Blvd.

Department of Psychology, 4S-108

Staten Island, NY 10314

irina.sekerina@csi.cuny.edu 